Article

\title{
Field Investigation of Hydraulic Fracturing in Coal Seams and Its Enhancement for Methane Extraction in the Southeast Sichuan Basin, China
}

\author{
Zuxun Zhang ${ }^{1,2}$, Hongtu Wang ${ }^{1,2}$, Bozhi Deng 1,2,*, Minghui Li ${ }^{1,2}$ and Dongming Zhang 1,2 \\ 1 State Key Laboratory of Coal Mine Disaster Dynamics and Control, Chongqing University, Chongqing \\ 400030, China; zxzhang89@163.com (Z.Z.); htwang@cqu.edu.cn (H.W.); cqumhli@foxmail.com (M.L.); \\ zhangdm@cqu.edu.cn (D.Z.) \\ 2 College of Resource and Environmental Sciences, Chongqing University, Chongqing 400030, China \\ * Correspondence: dengbz@cqu.edu.cn; Tel.: +86-023-65102421
}

Received: 25 October 2018; Accepted: 6 December 2018; Published: 10 December 2018

\begin{abstract}
Hydraulic fracturing is an effective technology for enhancing the extraction of reservoir methane, as proved by field experience and laboratory experiments. However, unlike conventional reservoirs, coal seams had high stress sensitivity and high anisotropy. Therefore, the efficiency of hydraulic fracturing in coal seams needs to be investigated. In this study, hydraulic fracturing was performed at Nantong mine in the southeast Sichuan basin, China. The field investigation indicated that the hydraulic fracturing could significantly enhance the methane extraction rate of boreholes ten times higher than that of normal boreholes in one of the minable coal seams (named \#5 coal seam). The performance of hydraulic fracturing in three districts revealed that compared with south flank, the fluid pressure was higher and the injection rate was lower in north flank. The methane extraction rate of south flank was inferior to that of north flank. It indicated hydraulic fracturing had less effect on \#5 coal seam in south flank. Moreover, the injection of high-pressure water in coal seams could also drive methane away from boreholes. The methane extraction rate of the test boreholes demonstrated the existence of methane enrichment circles after hydraulic fracturing. It indicated that hydraulic fracturing did act on \#5 coal seam in south flank. However, due to the high stress sensitivity of coal seams and the high geo-stress of south flank, the induced artificial fractures in \#5 coal seam might close with the decline of the fluid pressure that led to a sharp decline of the methane extraction rate.
\end{abstract}

Keywords: hydraulic fracturing; coal seam methane; field investigation; methane extraction; methane enrichment circle

\section{Introduction}

Methane disasters are the most threatening to safety in underground mining [1,2]. The original high methane pressure in coal seams might lead to a coal and gas outburst. Furthermore, coal seam methane is a clean energy resource. The extraction of coal seam methane can prevent methane disasters and can satisfy the growing demand for clean energy. However, the most minable coal seams in China have low or ultralow permeability, rendering it impossible to achieve the same permeability as in other countries (such as the United States and Australia) [3,4]. Low permeability restricts the extraction of methane in coal seams.

Coal seams are special reservoirs. The gas storage and permeability behaviors of coal seams are different from other porous reservoirs. Gray et al. [5] indicated that methane store in coal matrix by absorbing on porous' surface. The permeability of coal related to fluid pressure and shrinkage. The absorption property of coal is similar to that of shale, Jia et al. [6] found that the gas flow 
behavior in these porous media was affected by multiple physical process such as slip flow, absorption, pore diffusion and so on. Their studies both indicated that the effective stress had significant impact on coal permeability. Under the consideration of that matrix was incompressible, Mckee et al. [7] developed formulas to express the relationship between permeability, porosity, and effective stress. Underschultz et al. [8] reported the depressurization of coal seams during the process of gas associated water production. The decline of fluid pressure tends to close the cleats in coal and reduce permeability.

Many researchers have studied technologies that can enhance the permeability of coal seams [9-13]. Yan et al. [14] summarized 42 articles' achievements and comprehensively introduced hydraulic fracturing technology from eight aspects. Experience in the oil and gas industry has proved that hydraulic fracturing can enhance the permeability of reservoirs. However, the results of hydraulic fracturing are affected by many factors. Laboratory experimental studies indicated that the propagation of hydraulic fractures mostly depends on geological conditions. Zhou et al. [15] determined that different degrees of horizontal stress were likely to induce different fracture networks for hydraulic fracturing. Cheng et al. [16] found that geological and engineering parameters have a significant effect on hydraulic fracture propagation in natural fractured reservoirs. Cheng et al. [17] observed that the natural fractures in reservoirs were able to affect the performance of hydraulic fracturing. Guo et al. [18] performed computed tomography scanning on fractured specimens and found that the formation of internal fractures depends on multiple factors.

Recently, hydraulic fracturing has been used to increase the permeability of coal seams in underground mining systems. Differing from conventional reservoirs, coal seams have such characteristics as complex natural fractures, high stress sensitivity, and high anisotropy. Wright et al. [19] reported that several factors present challenges to hydraulic fracturing in coal seams, such as stress sensitivity and mechanical complexity of coal. Bohloli and de Pater [20] performed hydraulic fracturing in soft rocks and found that the confining pressure and the properties of the fracturing fluid determined the results of hydraulic fracturing. Li et al. [21] adopted a three-dimensional (3D) finite element model to investigate hydraulic fracturing in coal seams. The simulation results indicated that the heterogeneity of materials can cause fractures to branch, turn and twist. Wang et al. [22] derived empirical formulas for the breakdown pressure and fracture radius of hydraulic fracturing by using a particle flow code. Zhang et al. [23] regarded coal as a dual-porosity medium and used two-phase, $3 \mathrm{D}$, and hydraulic fracturing models to investigate increasing production of coalbed methane induced by hydraulic fracturing. Yang et al. [24] presented a coupled seepage damage model and simulated hydraulic fracturing around one hole and three holes. Numerical simulation results indicated that crack propagation paths were predominantly determined by the hydraulic gradient. Holditch et al. [25] found that many factors, such as high injection pressure and the production of coal fines, were harmful to the efficiency of hydraulic fracturing. Zou et al. [26] found that coal fines migration might plug the pore throat and result in a decrease of fracture conductivity during hydraulic fracturing.

In this study, hydraulic fracturing was performed in underground mining at the Nantong coalmine, Chongqing. The performance of hydraulic fracturing in the geological conditions in three districts were investigated and compared. The efficiency of methane extraction was considered the vital criterion for estimating hydraulic fracturing results. The effect of geological factors on hydraulic fracturing was analyzed based on the research results.

\section{Research Overview}

The Nantong coalmine of Nantong Coal Co., Ltd is in the south of Chongqing, China (Figure 1). There are six coal seams altogether in Nantong mine. These coal seams are named as \#1 \#6 from deep to shallow. \#4 \#6 coal seams are minable. The coal seams are divided into north and south flanks. The floor contour of the \#5 coal seam is shown in Figure 2. The coal seams in the north flank are relatively flat along the dip angle direction and are continuous. However, the floor contour of the \#5 coal seam occurs with a rotation in the south flank that implies the existence of a large-scale fold. The \#4, \#5, and \#6 coal seams are all coal and gas outburst coal seams. The original methane 
content of the coal seams is 16 to $23 \mathrm{~m}^{3} / \mathrm{t}$. The maximum methane pressure of the coal seams is $12 \mathrm{MPa}$. We have tested the permeability of coal both in field and laboratory. The test result of coal permeability is $1.25 \times 10^{-4} \mu \mathrm{m}^{2} \sim 2.00 \times 10^{-4} \mu \mathrm{m}^{2}$ in field. The test results of coal permeability and porosity are $0.408 \times 10^{-4} \mu \mathrm{m}^{2}$ and $5.18 \%$ in laboratory, respectively. Hence, a methane disaster in the Nantong mine would be serious. Because of the low permeability of the coal seams, the pre-extraction of coal seam methane is different; therefore, hydraulic fracturing technology has been employed to enhance the permeability of the \#5 coal seam in the mine since 2016.

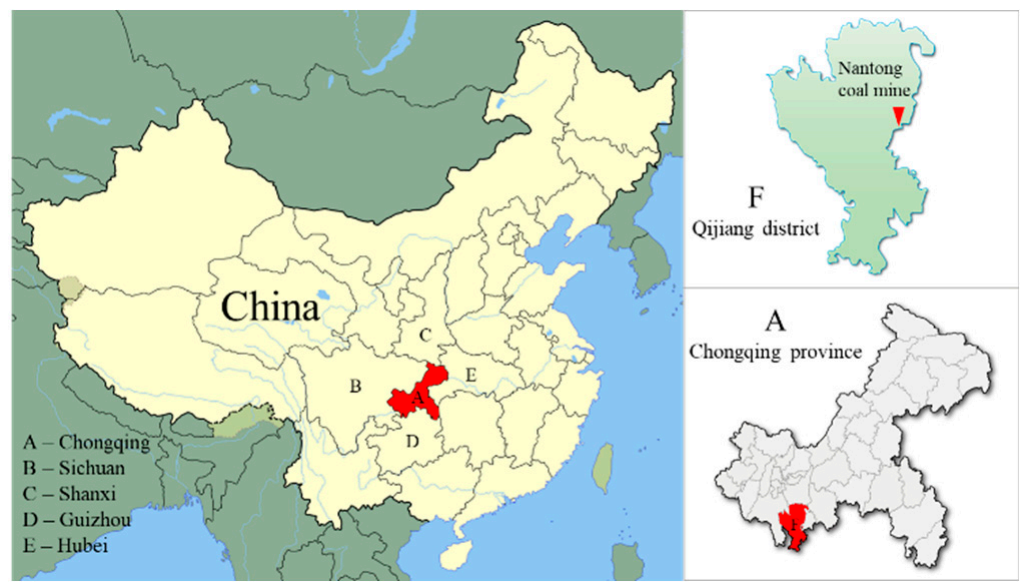

Figure 1. Location of Nantong coalmine.

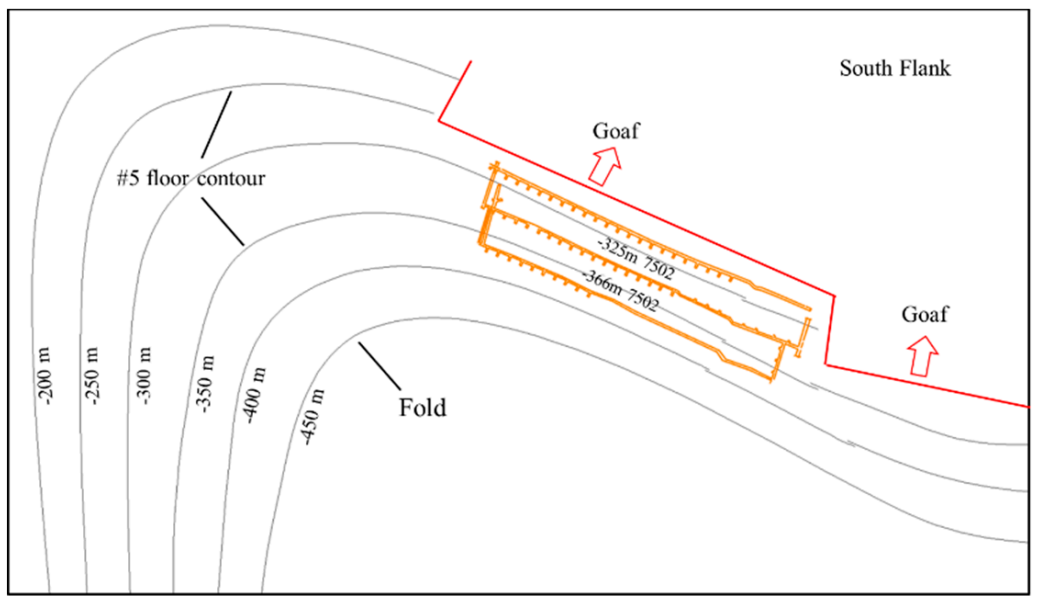

(a)

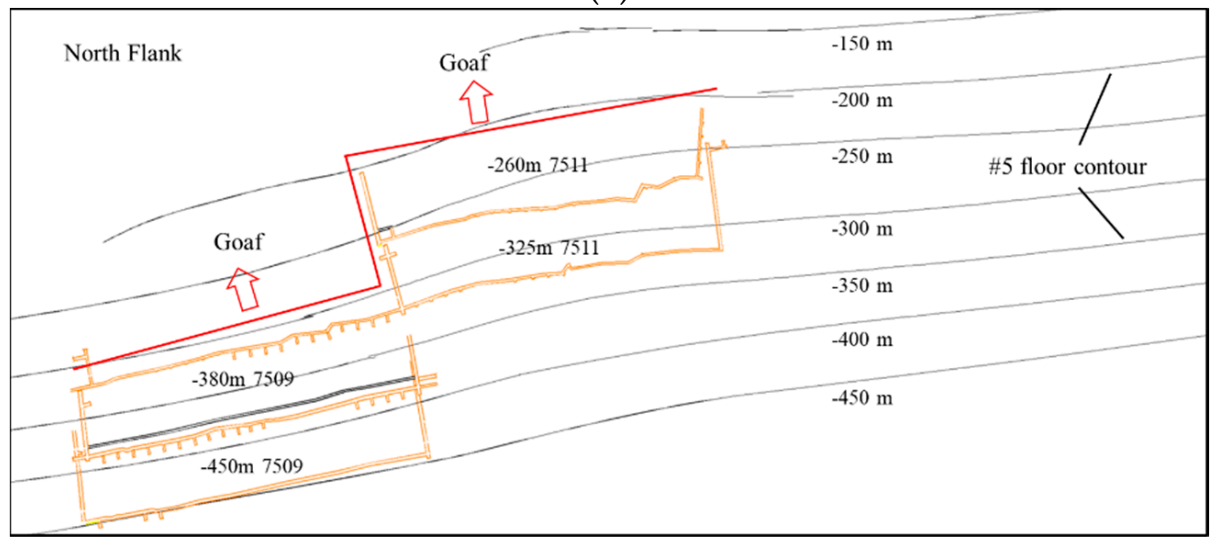

(b)

Figure 2. Floor contour of the \#5 coal seam. (a) South flank; (b) North flank. 


\section{Introduction of Hydraulic Fracture in Nantong Coalmine}

\subsection{Equipment for Hydraulic Fracturing}

A type BYW (Horizontal fracturing pump) fracturing pump system specifically designed for underground mining was employed to perform hydraulic fracturing in the \#5 coal seam. The entire weight of the fracturing pump system was $15,000 \mathrm{~kg}$. The length, width, and height were 9.04, 1.45, and $1.88 \mathrm{~m}$, respectively. The fracturing pump system involved electrical machinery, a hydraulic transmission device, and a main fracturing pump. The motive power generated by the electrical machinery caused an axle to rotate. The rotation speed was controlled by the hydraulic transmission device. The axle was linked to the plungers in the main fracturing pump though a gearbox and a crank that could turn the circular motion of the axle to the reciprocal motion of the plungers. Water was drawn into the main fracturing pump when the plungers moved rearward, and water was injected out of the main fracturing pump when the plungers moved forward. In this way, the water could be continuously injected into coal seams by the fracturing pump system. The fracturing pump system had five operating conditions to satisfy the complicated environment condition of hydraulic fracturing. The injection rate and fluid pressure of the five operating conditions are shown in Table 1. Water was adopted as fluid fracturing in Nantong mine. The property of water is shown in Table 2.

Table 1. Parameters of type BYW fracturing pump system.

\begin{tabular}{cccc}
\hline Operating Condition & Rotation Speed $(\mathbf{r a d} / \mathbf{m i n})$ & Injection Rate $\left(\mathbf{m}^{\mathbf{3}} \mathbf{h}\right)$ & Pressure $\mathbf{( M P a )}$ \\
\hline 5 & 370 & 70.5 & 16.5 \\
4 & 274 & 52.3 & 22 \\
3 & 184 & 35.1 & 33 \\
2 & 138 & 26.3 & 44 \\
1 & 92.5 & 17.6 & 50 \\
\hline
\end{tabular}

Table 2. Property of fracturing fluid.

\begin{tabular}{ccccc}
\hline District & Fracturing Fluid & Viscosity $(\boldsymbol{\mu P a} \cdot \mathbf{s})$ & Density $\left(\mathbf{g} / \mathbf{c m}^{\mathbf{3}}\right)$ & Temperature $\left({ }^{\circ} \mathbf{C}\right)$ \\
\hline-366 m 7502 & Water & 0.889 & 0.997 & 30 \\
$-260 \mathrm{~m} 7511$ & Water & 0.889 & 0.997 & 30 \\
$-325 \mathrm{~m} 7511$ & Water & 0.889 & 0.997 & 30 \\
\hline
\end{tabular}

\subsection{Procedure for Performing Hydraulic Fracturing}

In terms of the location, the hydraulic fracturing in the Nantong coalmine can be classified as roof roadway and crosscut roadway hydraulic fracturing. The roof roadway hydraulic fracturing is mainly discussed in this study. Roofs of \#5 coal seam are limestone (approximately $1.08 \mathrm{~m}$ ), calcareous shale (approximately $2.80 \mathrm{~m}$ ) and carbon mudstone (approximately $0.05 \mathrm{~m}$ ), respectively. The floors of \#5 coal seam are sandy shale (approximately $6.09 \mathrm{~m}$ ) and mudstone (approximately $3.20 \mathrm{~m}$ ). There is a hard limestone layer near the coal seam roof. Before the coal seam was mined, a roof was prepared, in the limestone layer (called the "Xi roadway"), which was specifically employed to pre-extract the corresponding coal seam methane. The crosscut boreholes for water injection were drilled from the $\mathrm{Xi}$ roadway to the coal seam. Generally, the fracturing pump system was placed in the main roadway near the location of hydraulic fracturing, because its significant weight and volume made transportation difficult in the Xi roadway. The crosscut boreholes were connected to the fracturing pump system by high-pressure water pipes. In this way, injecting water from the fracturing pump system into the \#5 coal seam was achieved. A diagram of the high-pressure water injection system is shown in Figure 3. The specific procedure of hydraulic fracturing in the roof roadway is as follows.

(1) In terms of the design of hydraulic fracturing, crosscut boreholes (diameter $90 \mathrm{~mm}$ ) are drilled in the $\mathrm{Xi}$ roadway. The crosscut boreholes must cross the roof and floor of the \#5 coal seam. 
(2) After drilling, special cement is used to seal the boreholes immediately to avoid collapse of the boreholes. Three pipes are prepared to seal the holes: a high-pressure water pipe for injecting water when performing hydraulic fracturing, one for injecting, and one to drain the cement paste. The sealing method is shown in Figure 4. The hydraulic pressure can be applied on the coal seams completely.

(3) After the cement paste is set, the high-pressure water pipe in the borehole is connected to the fracturing pump system and the hydraulic fracturing commences. Because the hydraulic fracturing might lead to the deformation of the $\mathrm{Xi}$ roadway, nobody is permitted to enter the $\mathrm{Xi}$ roadway until hydraulic fracturing is completed. The technician can control the injection rate and fluid pressure remotely for safety in the main roadway.

(4) When fracturing time reaches the design requirements, or water leak-off is found in the $\mathrm{Xi}$ roadway, the hydraulic fracturing is terminated. The high hydraulic pressure is unloaded, and the fracturing fluid is discharged by sump through the drainage system.

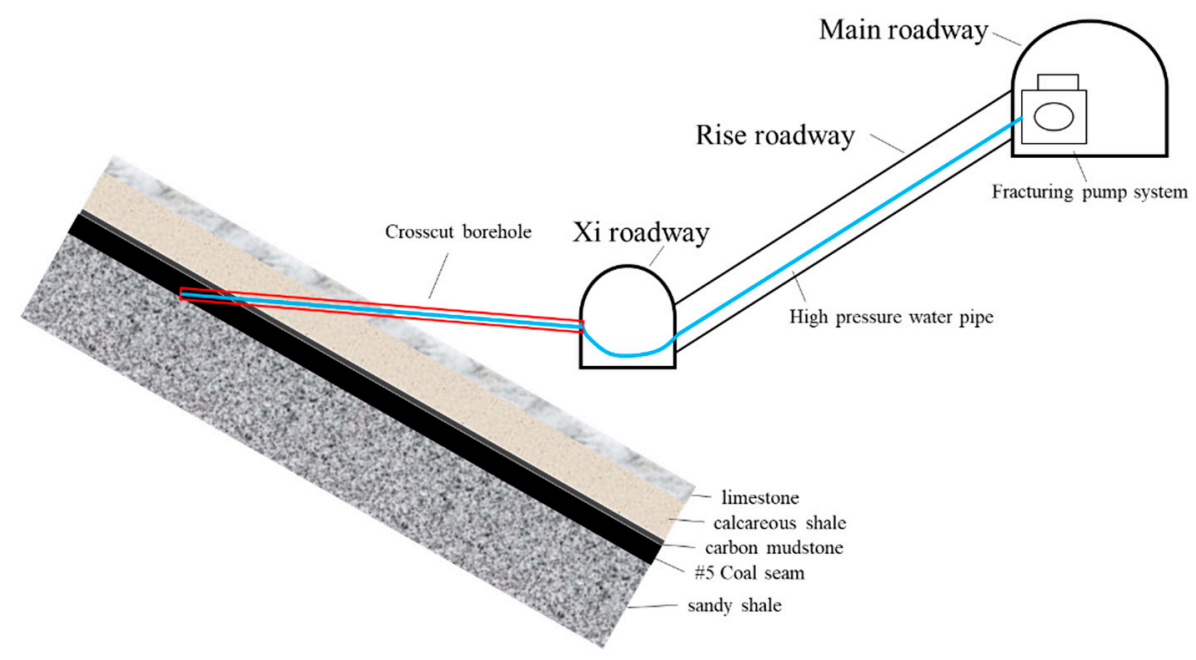

Figure 3. Sketch diagram of high-pressure water injection system.

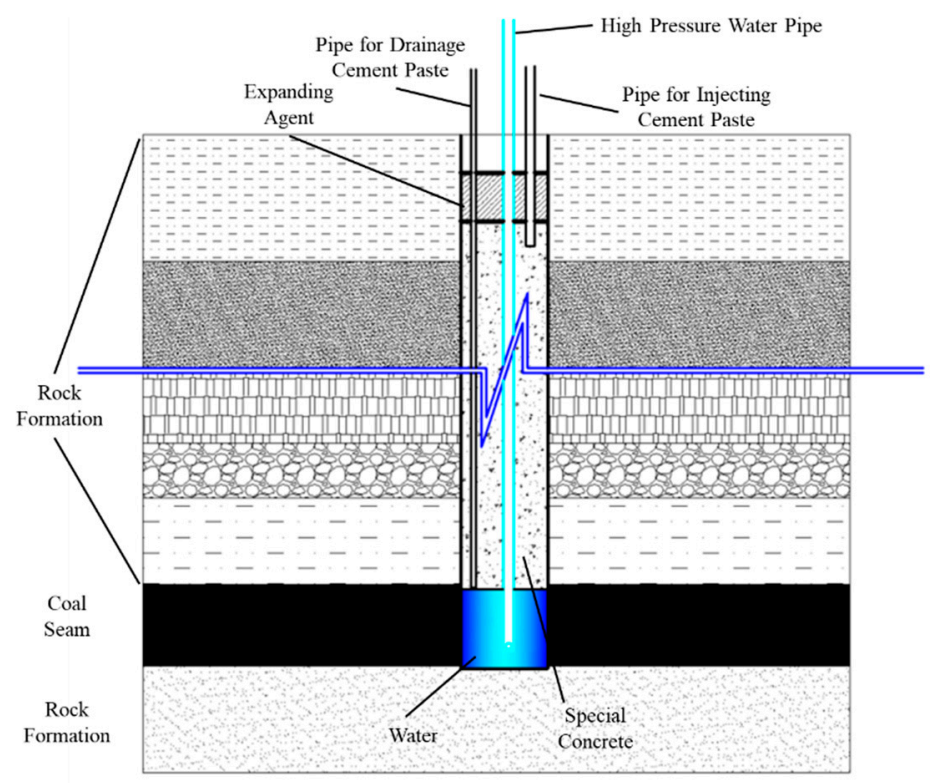

Figure 4. Sketch diagram of the seal method for hydraulic fracturing. 


\subsection{Hydraulic Fracturing Site}

Hydraulic fracturing data from three districts were collected and analyzed to investigate the field characteristics of underground hydraulic fracturing in the Nantong coalmine. The surrounding geological conditions of the three districts were as follows.

(1) $-260 \mathrm{~m} 7511$ district ( $-260 \mathrm{~m}$ represents the depth of the district, and 7511 is the serial number of the district)

The $-260 \mathrm{~m} 7511$ district is in the north flank of the Nantong coalmine $-260 \mathrm{~m}$ underground. Currently, it is the most northern district in the coalmine. The mining division shows that the height of $-260 \mathrm{~m} 7511$ district is from $-184 \mathrm{~m}$ to $-260 \mathrm{~m}$, the length of the district is approximately $416 \mathrm{~m}$ along the \#5 coal seam strike from the ninth to the eleventh crosscut roadway. The thickness of the \#5 coal seam in this district is from 0.26 to $1.18 \mathrm{~m}$. The angle of the coal seam is from $27^{\circ}$ to $34^{\circ}$. Districts to the south and adjacently above have been mined, while the north and lower districts have not yet been mined.

(2) $-325 \mathrm{~m} 7511$ district

The $-325 \mathrm{~m} 7511$ district is the lower adjacent district of the $-260 \mathrm{~m} 7511$ district and is in the north flank of the Nantong coalmine at $-325 \mathrm{~m}$ underground. Currently, it is the most northern district in the coal mine. The mining division shows that the height of the $-325 \mathrm{~m} 7511$ district is from -260 to $-325 \mathrm{~m}$, and the length of the district is approximately $416 \mathrm{~m}$ along the \#5 coal seam strike from the ninth to the eleventh crosscut roadway. The thickness of the \#5 coal seam in this district is from 0.62 to $1.40 \mathrm{~m}$. The angle of the coal seam is from $27^{\circ}$ to $34^{\circ}$. The south adjacent districts have been mined, while the north, upper, and lower districts have not been mined.

(3) $-366 \mathrm{~m} 7502$ district

The $-366 \mathrm{~m} 7502$ district is in the south flank of the Nantong coalmine $-366 \mathrm{~m}$ underground. Currently it is the second deepest district in the coalmine. The mining division shows that the height of the $-325 \mathrm{~m} 7511$ district is from -325 to $-366 \mathrm{~m}$, and the length of the district is approximately $517 \mathrm{~m}$ along the \#5 coal seam strike from the fourth to the second crosscut roadway. The thickness of the \#5 coal seam in this district is $0.4 \mathrm{~m}$ to $1.1 \mathrm{~m}$. The angle of the coal seam is from $33^{\circ}$ to $36^{\circ}$. None of the adjacent districts have been mined.

\section{Observations during Hydraulic Fracturing}

According to the design requirement, 11 crosscut boreholes were drilled for performing hydraulic fracturing in the $-260 \mathrm{~m} 7511$ district, seven crosscut boreholes were drilled in the $-325 \mathrm{~m} 7511$ district, and 13 crosscut boreholes were drilled in the $-366 \mathrm{~m} 7502$ district. Because there were too many crosscut boreholes in the three districts, for brevity, a representative borehole was selected from every district to investigate the characteristics of hydraulic fracturing. The design drawing of three representative borehole is shown in Figure 5. In Figure 5 A-A, B-B and C-C represent the positions of profile figure. $30^{\circ}, 29^{\circ}$ and $30^{\circ} 30^{\prime}$ represent the dip angles of $\# 5$ coal seam. $5.93 \mathrm{~m}, 8.73 \mathrm{~m}$ and $5.1 \mathrm{~m}$ represent the minimum distance from $X i$ roadway to \#5 coal seam.

\subsection{Variation of Fluid Pressure and Injection Rate}

The \#7 borehole was selected to investigate the characteristics of hydraulic fracturing in the $-260 \mathrm{~m} 7511$ district. The hydraulic fracturing in the \#7 borehole lasted $17 \mathrm{~h} 40 \mathrm{~min}$. Three operating conditions $1 \sim 3$ of the fracturing pump system were used to perform hydraulic fracturing. The injection rate was 11 to $22 \mathrm{~m}^{3} / \mathrm{h}$, and the fluid pressure was 32 to $36 \mathrm{MPa}$. Finally, $320 \mathrm{~m}^{3}$ of water was injected into the \#7 borehole to perform hydraulic fracturing. 

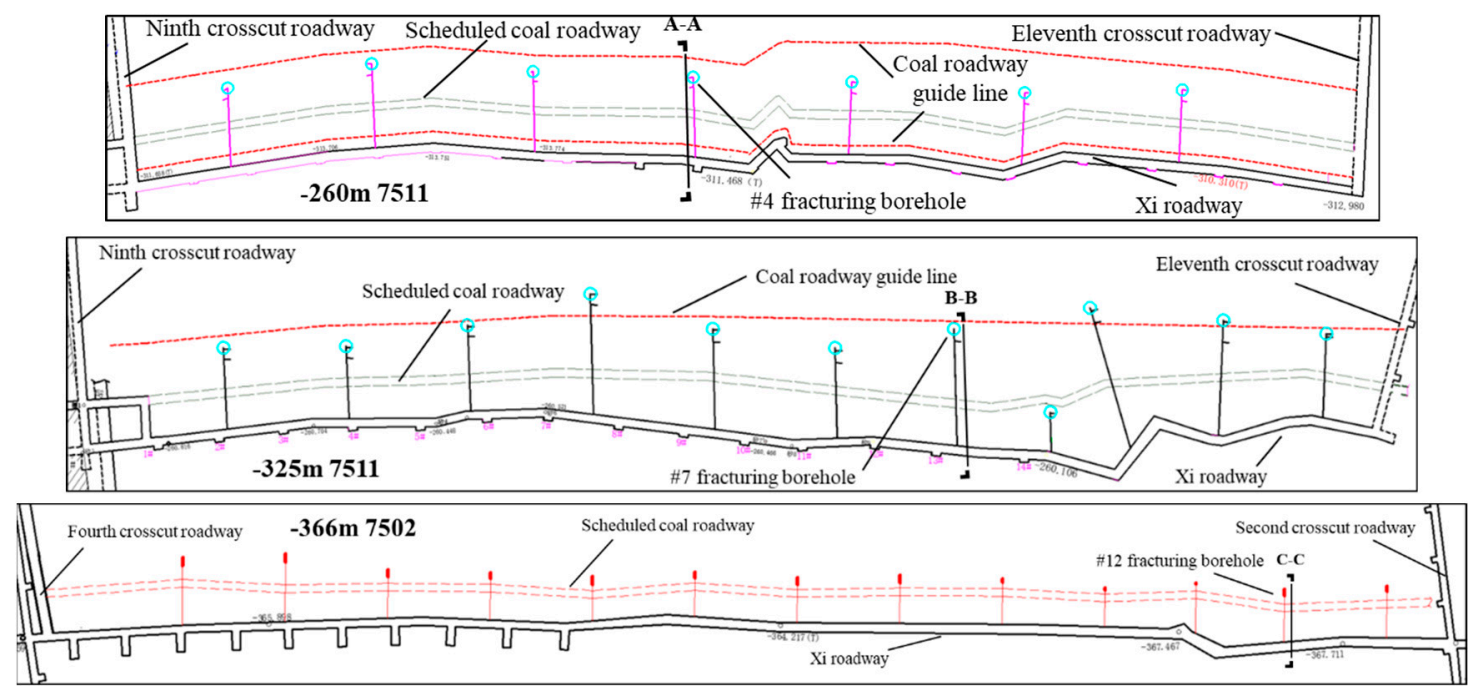

(a)

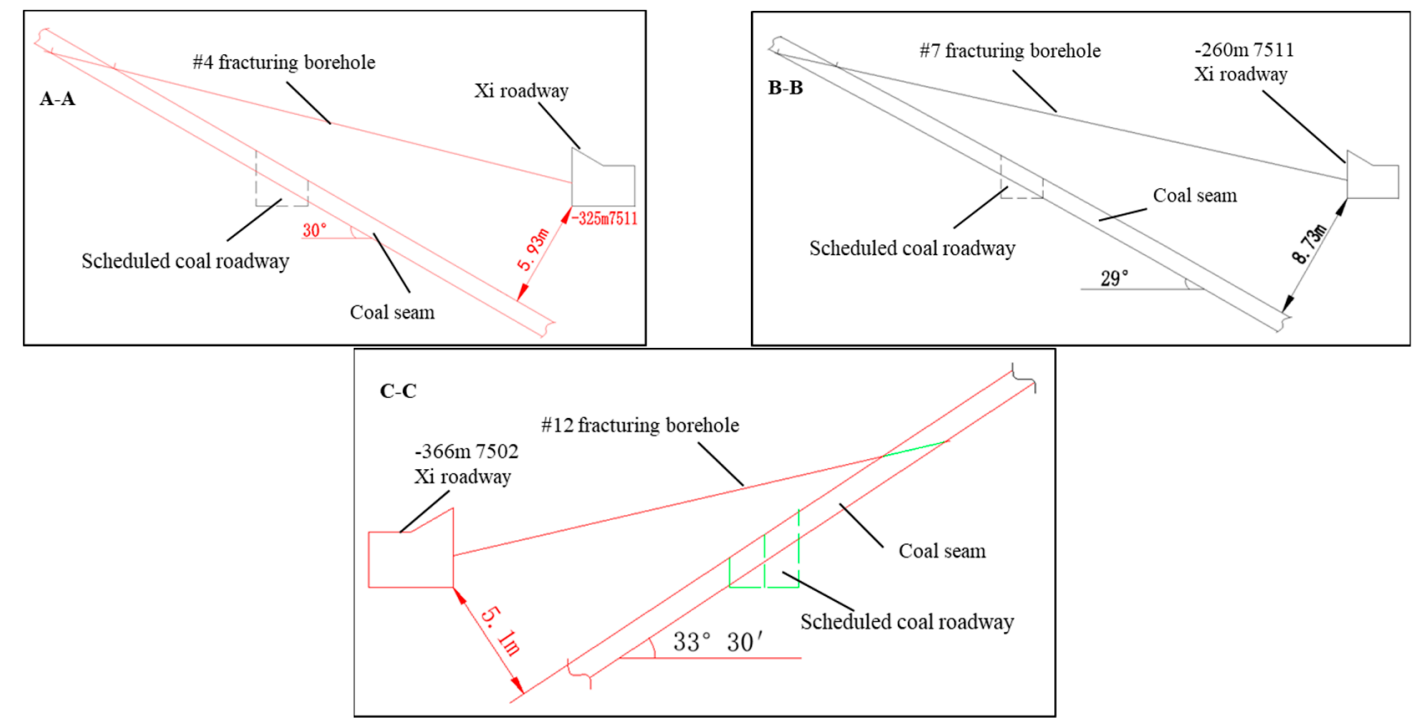

(b)

Figure 5. Design drawings of hydraulic fracturing in the three districts. (a) Plane figure; (b) Profile figure.

The \#4 borehole was selected to investigate the characteristics of hydraulic fracturing in the $-325 \mathrm{~m} 7511$ district. The hydraulic fracturing in the \#4 borehole lasted $15 \mathrm{~h} 44 \mathrm{~min}$. Only one operating condition 3 of the fracturing pump system was used to perform hydraulic fracturing. The injection rate was 23 to $24 \mathrm{~m}^{3} / \mathrm{h}$, and the fluid pressure was 25 to $28 \mathrm{MPa}$. Finally, $357 \mathrm{~m}^{3}$ of water was injected into the \#4 borehole to perform hydraulic fracturing.

The \#12 borehole was selected to investigate the characteristics of hydraulic fracturing in the $-366 \mathrm{~m} 7502$ district. The hydraulic fracturing in the \#12 borehole lasted $11 \mathrm{~h} 30 \mathrm{~min}$. Two operating conditions 1 and 2 were switched, according to the decline of fluid pressure. At the beginning, operating condition 1 was used to perform hydraulic fracturing. The fluid pressure could reach 31 to $34 \mathrm{MPa}$ when the injection rate was 5 to $12 \mathrm{~m}^{3} / \mathrm{h}$. The leak-off of water increased with fracture propagation in the \#5 coal seam. Consequently, the fluid pressure declined under the low injection rate. Therefore, a higher injection rate of 19 to $20 \mathrm{~m}^{3} / \mathrm{h}$, was adopted, and the fluid pressure reached 34 to $41 \mathrm{MPa}$. Finally, $185 \mathrm{~m}^{3}$ of water was injected into the \#12 borehole to perform hydraulic fracturing.

Although the injection rate and fluid pressure for hydraulic fracturing were studied in only three boreholes, the injection rate and fluid pressure in the three boreholes were representative. Comparing the overall situation of hydraulic fracturing in the three districts, operating condition 3 (high injection 
rate) was frequently used to perform hydraulic fracturing in the $-260 \mathrm{~m}$ and $-325 \mathrm{~m} 7511$ districts. The fluid pressure generally was less than $35 \mathrm{MPa}$ in these two districts, and the fluid pressure was less than $30 \mathrm{MPa}$ in the $-325 \mathrm{~m} 7511$ districts. However, operating conditions 1 and 2 were frequently used in the $-366 \mathrm{~m} 7502$ district. Almost all the injection rates were less than $20 \mathrm{~m}^{3} / \mathrm{h}$ in the $-366 \mathrm{~m}$ 7502 districts. Almost all the fluid pressure was more than $35 \mathrm{MPa}$, and the highest fluid pressure was as much as $41 \mathrm{MPa}$.

The fluid pressure and injection rate are documented in Figure 6. Comparing the observed differences of fluid pressure in the three districts reveals that the fluid pressure of hydraulic fracturing in the $-366 \mathrm{~m} 7502$ district was significantly higher than in the other districts. This implies that the geo-stress in the $-366 \mathrm{~m} 7502$ district is higher than in the other districts. Comparison of the observed differences of injection rates in the three districts shows that the injection rate of hydraulic fracturing in the $-366 \mathrm{~m} 7502$ district was significantly lower than in the other districts. This implies that the leak-off of fracturing fluid in $-366 \mathrm{~m} 7502$ district may be lower than in the other districts, probably as a result of the natural fracture differences between the districts.

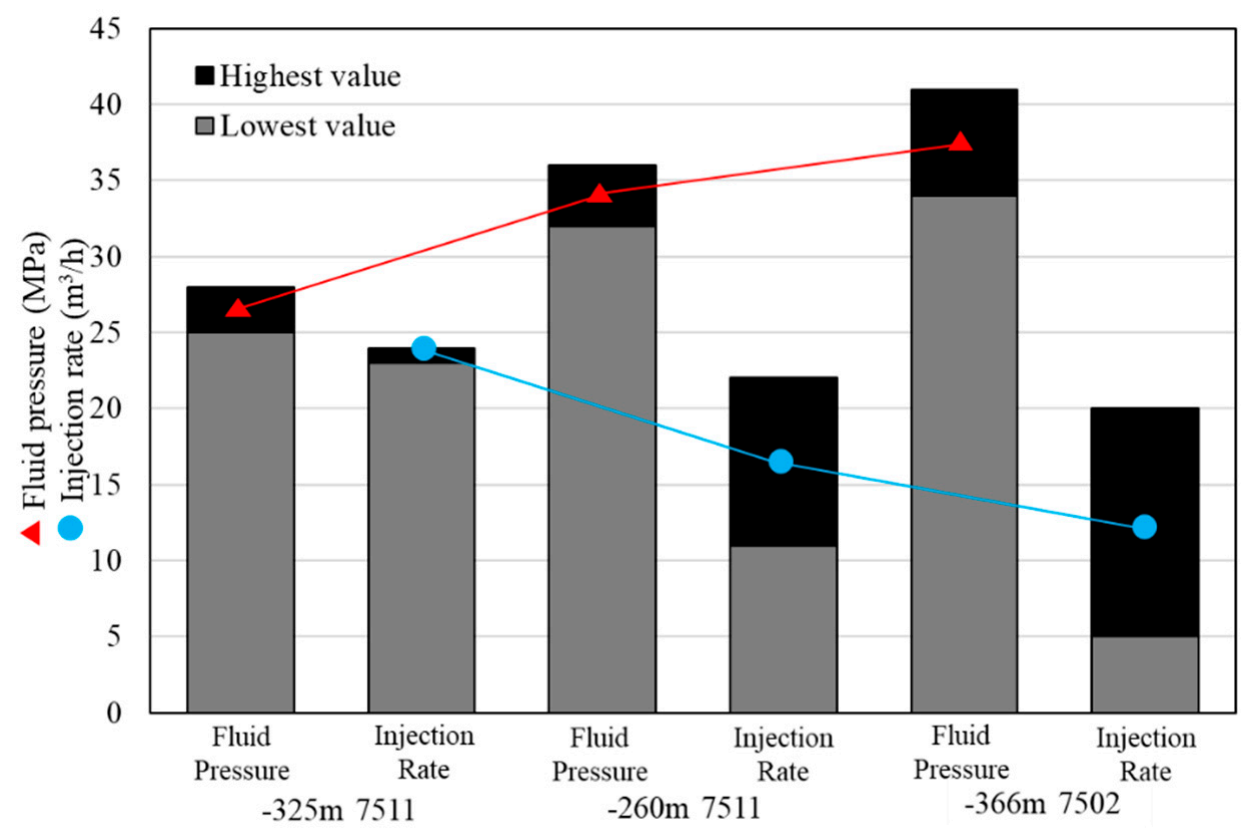

Figure 6. Operating parameters of hydraulic fracturing in the three districts.

\subsection{Variations of Surrounding Rocks}

The \#7, \#4, and \#12 boreholes were also used as analysis examples for the surrounding rocks in the $-260 \mathrm{~m} 7511,-325 \mathrm{~m} \mathrm{7511}$, and $-366 \mathrm{~m} 7502$ districts, respectively. The variation of the surrounding rocks during hydraulic fracturing in the three boreholes is shown in Figure 7 . When the hydraulic fracturing ended in the \#7 borehole, $-260 \mathrm{~m} 7511$ district, the surrounding rocks located approximately 10 and $30 \mathrm{~m}$ north of \#7 borehole were found to have water leak-off. When the hydraulic fracturing lasted approximately $9 \mathrm{~h}$ in the \#4 borehole, $-325 \mathrm{~m} 7511$ district, the surrounding rocks located approximately $5 \mathrm{~m}$ south of the \#4 borehole and approximately $30 \mathrm{~m}$ north of the \#4 borehole experienced floor heave. When the hydraulic fracturing lasted approximately $8 \mathrm{~h}$ in the \#12 borehole, $-366 \mathrm{~m} 7502$ district, the surrounding rocks located approximately 1 to $2 \mathrm{~m}$ around the \#12 borehole experienced a slight floor heave. 


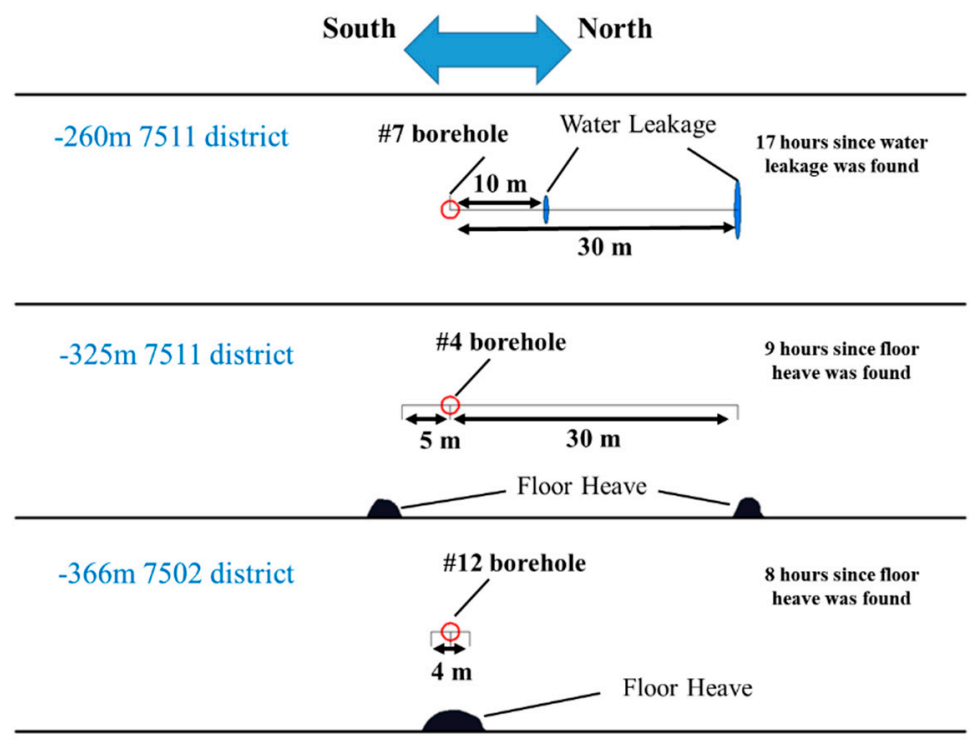

Figure 7. Variation of surrounding rocks in the three districts.

Comparing the differences of the surrounding rocks in the three districts shows that the variations of the surrounding rocks in the $-260 \mathrm{~m}$ and $-325 \mathrm{~m} 7511$ districts were greater than in the $-366 \mathrm{~m}$ 7502 district. This implies that the effect of hydraulic fracturing in the $-260 \mathrm{~m}$ and $-325 \mathrm{~m} 7511$ districts may be more significant than that in the $-366 \mathrm{~m} 7502$ district.

\subsection{Enhancement of Methane Extraction}

After hydraulic fracturing, the process of draining water from crosscut boreholes lasted approximately 1 to 2 weeks. Then, the high-pressure pipes were linked to the extraction system in the coalmine for extracting methane from the \#5 coal seam. The extraction conditions of the boreholes were measured in the $-260 \mathrm{~m} \mathrm{7511,}-325 \mathrm{~m} 7511$, and $-366 \mathrm{~m} 7502$ districts. The methane concentration and methane extraction rate were the crucial data for estimating the effects of methane extraction. The variations of the methane concentration and methane extraction rate with time for the \#7, \#4, and \#12 boreholes are shown in Figure 8 for the $-260 \mathrm{~m} \mathrm{7511,}-325 \mathrm{~m} \mathrm{7511}$, and $-366 \mathrm{~m}$ 7502 districts, respectively. Hydraulic fracturing could significantly enhance the methane extraction, considered that the average methane extraction rate of the extraction borehole in the \#5 coal seam was only 0.01 to $0.005 \mathrm{~m}^{3} / \mathrm{min}$. The initial methane extraction rate of the three boreholes could reach approximately $0.1 \mathrm{~m}^{3} / \mathrm{min}$, which is ten times higher than the methane extraction rate of the average extraction borehole. However, unlike the other districts, in the $366 \mathrm{~m} 7502$ district, the decline of the methane extraction rate was significant in the \#12 borehole, probably because of geological factors. The variation of methane extraction rates of all boreholes with time are shown in Figure 9 for the $-260 \mathrm{~m} \mathrm{7511},-325 \mathrm{~m} 7511$, and $-366 \mathrm{~m} 7502$ districts. The methane extraction rate of all the boreholes had a similar variation tendency as that of the selected boreholes. Therefore, the characteristics of hydraulic fracturing in the selected boreholes were representative.

The result of methane extraction shows that the methane extraction rate of the boreholes in the $-366 \mathrm{~m} 7502$ district declined earlier than that of the boreholes in the other districts. After the decline of the methane extraction rate in the $-366 \mathrm{~m} 7502$ districts, the residual methane content of the $\# 5$ coal seam was measured. The measured results indicated that the residual methane content was $11.87 \mathrm{~m}^{3}$ per ton $\left(\mathrm{m}^{3} / \mathrm{t}\right)$. Compared with the original methane content of the \#5 coal seam, the residual methane content did not reduce significantly. This implies that hydraulic fracturing in the $-366 \mathrm{~m} 7502$ district was not as effective as in the other districts. 

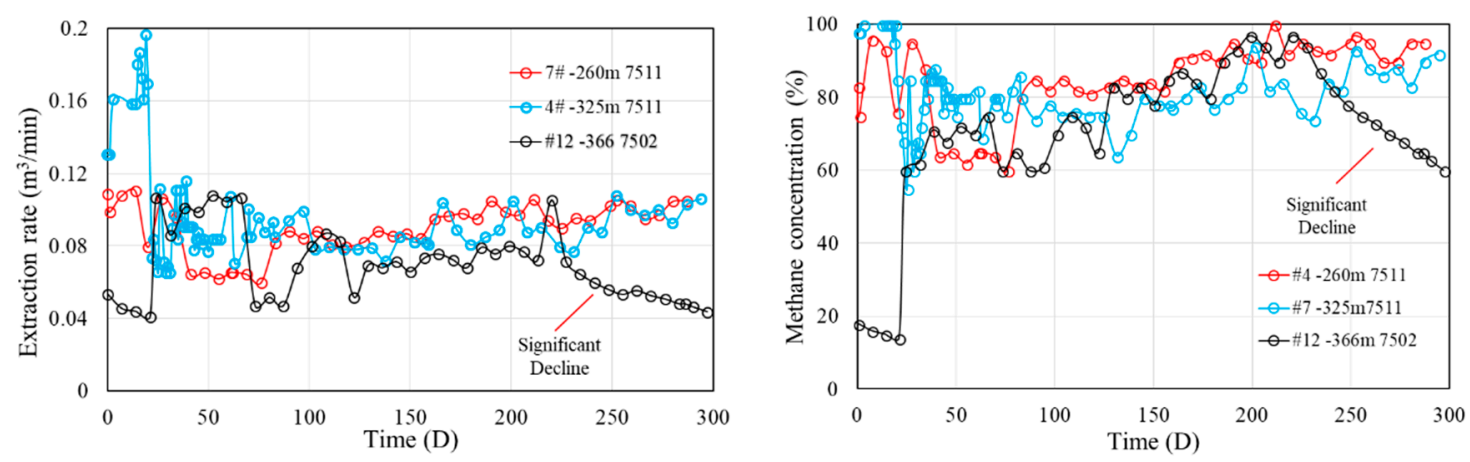

Figure 8. Variations of methane concentration and methane extraction rate with time.

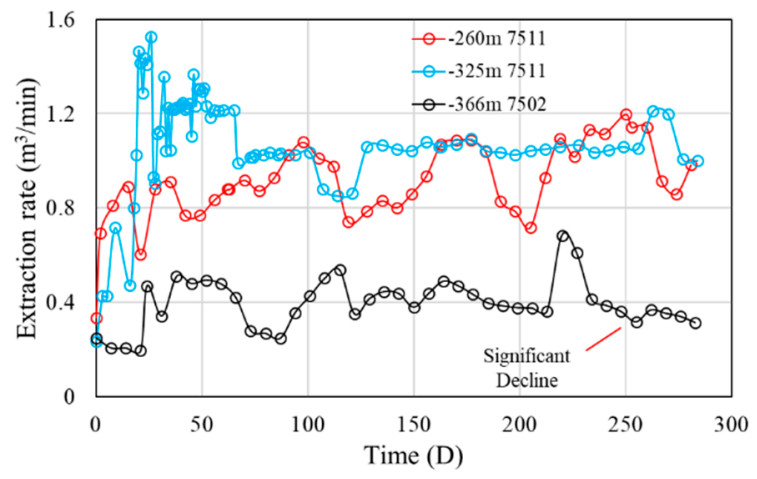

Figure 9. Variations of methane extraction rate of the whole boreholes with time.

\section{Discussion}

\subsection{Effect of Geo-Stress}

Geological factors have been widely considered as crucial factors for performing hydraulic fracturing in reservoirs. Similarly, it was observed that geological factors regulated the performance of hydraulic fracturing in the Nantong coalmine. We considered three geological factors that affected the hydraulic fracturing. The first was the elevation of the target coal seam. The $-366 \mathrm{~m} 7502$ district is the deepest district among three districts, which implies that the vertical stress is likely to be the largest in that district. Second, the coal seams in the north flank are relatively flat along the dip angle direction and are continuous, but there is only a large geological structure in the north flank. However, the floor contour of the \#5 coal seam exhibits rotation in the south flank, which implies the existence of a large fold. The $-366 \mathrm{~m} 7502$ district is near the center of the fold, which results in the concentration of horizontal stress. In addition, mining activity is likely to lead to the redistribution of geo-stress. The brief view of the hydraulic fracturing site implies that mining activity near the $-260 \mathrm{~m}$ and $-325 \mathrm{~m}$ 7511 districts might reduce the geo-stress of the \#5 coal seam there. In general, the original geo-stress or the redistributed geo-stress of the \#5 coal seam in $-366 \mathrm{~m} 7502$ district is higher than that in the other districts.

The performance of fluid pressure for hydraulic fracturing also conformed to the geological investigation. The fluid pressure (41 MPa) in the $-366 \mathrm{~m} 7502$ district was more significant than that (30 to $35 \mathrm{MPa}$ ) in the other districts. Furthermore, the high geo-stress causes natural fractures to close, which results in a decrease of water leakage. Therefore, the injection rate was low, although it was possible to attain high fluid pressure in the $-366 \mathrm{~m} 7502$ district.

Although the geo-stress was high, the type BYW fracturing pump system was still adequate to satisfy the requirements of performing hydraulic fracturing in the $-366 \mathrm{~m} 7502$ district. On average, $219 \mathrm{~m}^{3}$ of water per borehole was injected into the $\# 5$ coal seam, and hydraulic fracturing was supposed to influence methane extraction in the $-366 \mathrm{~m} 7502$ district. However, the enhancement of methane 
extraction was not as expected. Therefore, the results of hydraulic fracturing in the $-366 \mathrm{~m} 7502$ district were investigated in depth.

\subsection{Methane Enrichment Circle}

During hydraulic fracturing, the high-pressure water fractured coal seams and entered the matrix pores and fractures. This resulted in an increase of pore and fracture pressures in the coal seams, which caused methane to migrate to areas of low pore or fracture pressure. This implies that methane around the fracturing borehole will be driven away from the borehole until the fluid pressure in pores or fractures is reduced. Because the high-pressure water flow in coal seams belongs to the radial flow, the methane around the fracturing borehole will migrate radially along the pressure gradient and form a methane enrichment circle. The methane enrichment circle should continually keep away from the fracturing boreholes, as shown in Figure 10, until hydraulic fracturing is stopped. The methane content of the coal seams inside the methane enrichment circle was reduced, which was detrimental to methane extraction, whereas the methane content of the coal seams near the methane enrichment circle was enhanced, which was beneficial for methane extraction.

Coal seam methane was not extracted from the \#8 borehole in the $-366 \mathrm{~m} 7502$ district after hydraulic fracturing. Based on the theory of the methane enrichment circle, eight test boreholes were drilled around the \#8 borehole to investigate the results of hydraulic fracturing. The location relationships between test boreholes and the \#8 borehole are shown in Figure 11. Coal seam methane was extracted from these test boreholes. The methane extraction rate and concentration were measured during the extraction process. The measured data are shown in Figure 12. Figure 12 shows that the methane extraction rate and concentration in the boreholes near the \#8 borehole were lower than in the boreholes away from the $\# 8$ borehole. The results of the methane extraction in test boreholes proved the existence of a methane enrichment circle in the $-366 \mathrm{~m} 7502$ district.

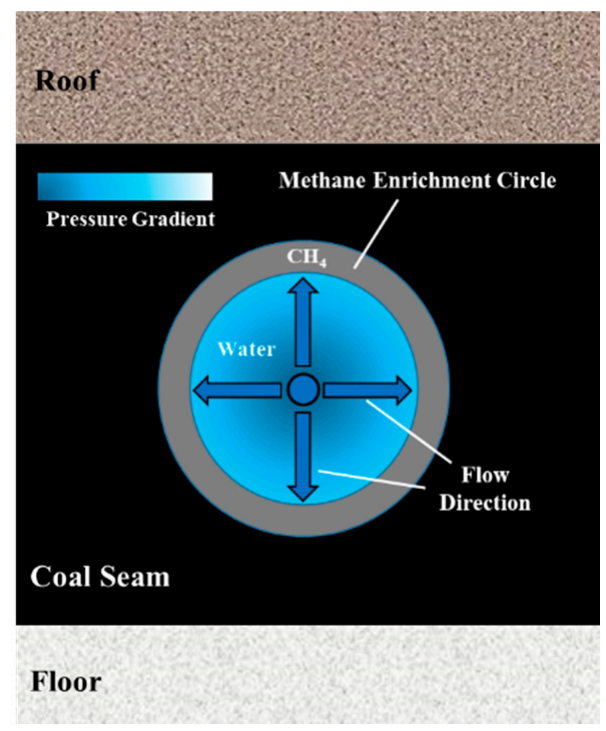

Figure 10. Schematic diagram of methane enrichment circle.

The methane enrichment circle in the $-366 \mathrm{~m} 7502$ district also indicated that the high-pressure water affected the \#5 coal seam during hydraulic fracturing. However, the effect of hydraulic fracturing on methane extraction was not significant. This might be because the methane extraction not only depended on the results of hydraulic fracturing, but also relied on the closure of induced artificial fractures. Because of the superior performance of the fracturing pump system, the hydraulic fracturing could induce fractures to enhance the permeability of the \#5 coal seam. However, the coal was easily compressed (stress sensitive). Furthermore, proppant was not added to the fracturing fluid to prop artificial fractures open. Therefore, the induced artificial fractures closed as the fluid pressure declined, 
which resulted in a reduction of the permeability of the fractured coal seams and a decline of the methane extraction rate.

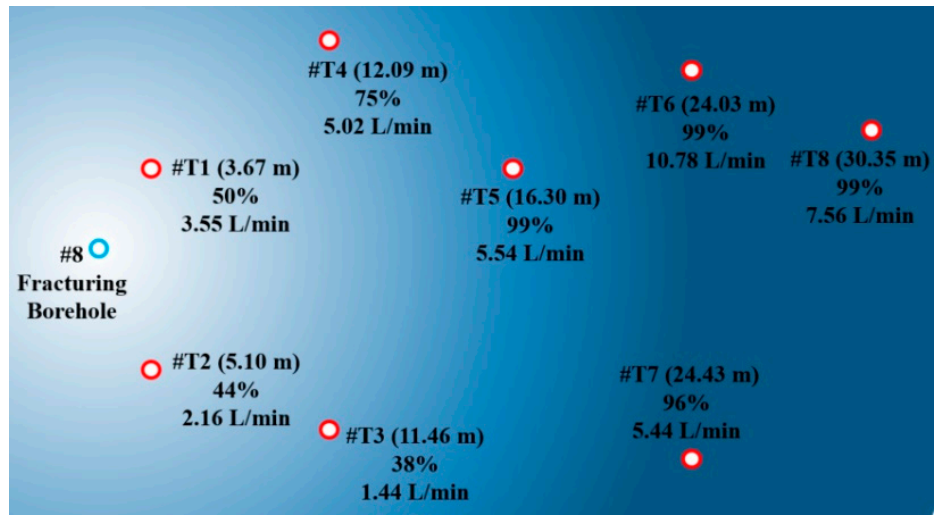

Figure 11. Location relationship between test boreholes and the \#8 fracturing borehole.
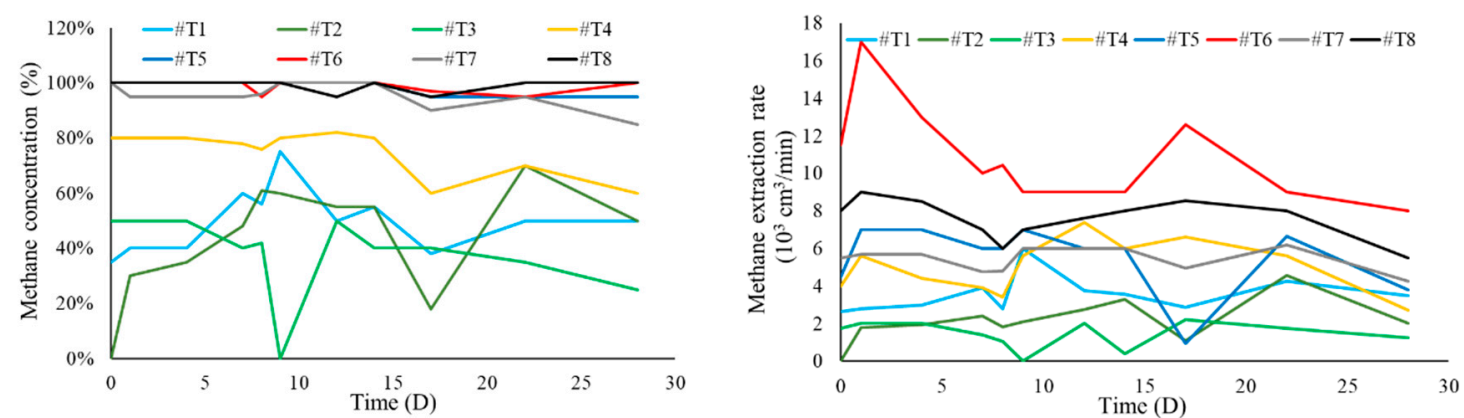

(a)

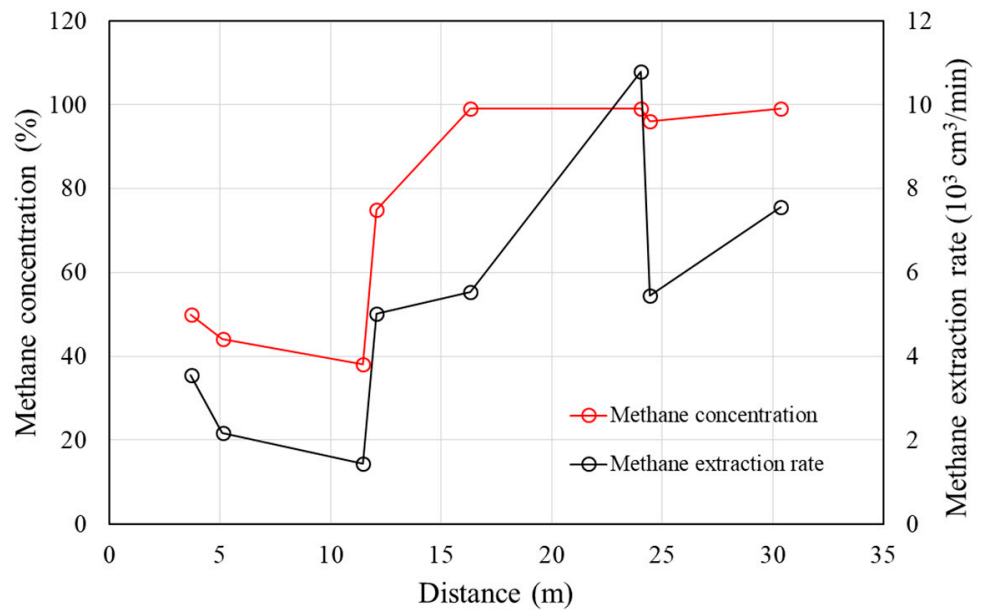

(b)

Figure 12. Variation of methane extraction rate and concentration in test boreholes. (a) With time; (b) With distance.

\subsection{Effect of Heterogeneity and Reservoir Complexity}

Differing from normal reservoirs, coal seams contain many natural fractures which would enhance the reservoir complexity and impact the results of hydraulic fracturing. Many studies [27,28] investigated the effect hydraulic fracturing in complex reservoirs. They found that the interaction between hydraulic fractures and natural fractures might restrain the formation of simple, long effective, vertical fractures, that reduced the influence area of hydraulic fracturing and even produced wellbore failure. Therefore, the effect of heterogeneity and fracture complexity must be considered for hydraulic fracturing in coal seams. 
As Section 5.2 mentioned, the $-366 \mathrm{~m} 7502$ district is near the center of a fold. Based on the characteristic of folds, the compressive and tensile effect of horizontal stress could induce natural fractures and decline the continuity of the coal seams in $-366 \mathrm{~m} 7502$ district. Due to the high complexity of natural fractures, the hydraulic fractures might propagate along the natural fractures, rather than forming effective, long, and vertical fractures in the $-366 \mathrm{~m} 7502$ district. It might lead to that the influence area of hydraulic fracturing in the $-366 \mathrm{~m} 7502$ district was less than that in other districts.

According to the variations of surrounding rocks, it was found that the influence area of hydraulic fracturing in the $-260 \mathrm{~m}$ and $-325 \mathrm{~m} 7511$ districts were larger than that in the $-366 \mathrm{~m} 7502$ district. The performance of surrounding rocks during hydraulic fracturing also conformed to the geological investigation. Therefore, the poor enhancement of methane extraction in the $-366 \mathrm{~m} 7502$ district might be caused by the small influence are of hydraulic fracturing.

\section{Conclusions}

Hydraulic fracturing was adopted to enhance methane extraction in the Nantong coalmine. The performance of hydraulic fracturing, including fluid pressure, injection rate, rock surrounding roadways, and the methane extraction conditions, was investigated in three districts. Geological characteristics were considered the crucial factor that affected hydraulic fracturing. The differences in performance of hydraulic fracturing and the geological factors in three districts were analyzed. The main conclusions are as follows.

(1) Performing hydraulic fracturing for the \#5 coal seam made it possible to enhance methane extraction in the coal seam. The methane extraction rate of a single fracturing borehole could reach $0.1 \mathrm{~m}^{3} /$ min which was approximately ten times compared to an average extraction borehole.

(2) The performance of hydraulic fracturing and the variations of surrounding rocks conformed to the analysis of geological factors. It indicated that the geological factors, such as coal seams depth and geological structure, had a significant effect on hydraulic fracturing.

(3) Near hydraulic fracturing boreholes, the methane extraction concentration of the test boreholes was below $75 \%$. While the methane extraction concentration of the test boreholes which were away from hydraulic fracturing boreholes could reach $90 \%$. The methane extraction data for the test boreholes indicated the existence of a methane enrichment circle after hydraulic fracturing.

(4) Because of the high stress sensitivity of coal, the induced artificial fractures in coal seams closed with the decline of fluid pressure. High geo-stress could lead to a sharp decline of the methane extraction rate.

Author Contributions: Z.Z., M.L. carried out the test of Methane enrichment circle, participated in data analysis; H.W., D.Z., participated in the design of the field hydraulic fracturing in Nantong coalmine; B.Z. participated in data analysis and drafted the manuscript; all authors gave final approval for publication.

Funding: This research received no external funding.

Acknowledgments: The authors appreciate the suggestion and help provided by the engineers in Nantong coalmine, when we designed hydraulic fracturing and the test of enrichment methane circle. Moreover, the authors appreciate that the staffs of methane department helped to carry out hydraulic fracturing and methane extraction in Nantong coalmine. There is no funding for this research.

Conflicts of Interest: The authors declare no conflict of interest.

\section{References}

1. Wang, H.F.; Cheng, Y.P.; Yuan, L. Gas outburst disasters and the mining technology of key protective seam in coal seam group in the Huainan coalfield. Nat. Hazards 2013, 67, 763-782. [CrossRef]

2. Liu, Y.K.; Zhou, F.B.; Liu, L.; Liu, C.; Hu, S.Y. An experimental and numerical investigation on the deformation of overlying coal seams above double-seam extraction for controlling coal mine methane emissions. Int. J. Coal Geol. 2011, 87, 139-149. 
3. Karacan, C.O.; Ruiz, F.A.; Cote, M.; Phipps, S. Coal mine methane: A review of capture and utilization practices with benefits to mining safety and to green- house gas reduction. Int. J. Coal Geol. 2011, 86, 121-156. [CrossRef]

4. Xia, T.; Zhou, F.; Liu, J.; Gao, F. Evaluation of the pre-drained coal seam gas quality. Fuel 2014, 130, $296-305$. [CrossRef]

5. Gray, I. Reservoir Engineering in Coal Seams: Part 1The Physical Process of Gas Storage and Movement in Coal Seams. SPE Reserv. Eng. 1987, 2, 28-34. [CrossRef]

6. Jia, B.; Tsau, J.; Barati, R.A. Workflow to Estimate Shale Gas Permeability Variations during the Production Process. Fuel 2018, 220, 879-889. [CrossRef]

7. Mckee, C.R.; Bumb, A.C.; Koenig, R.A. Stress-Dependent Permeability and Porosity of Coal and Other Geologic Formations. SPE Form. Eval. 1988, 3, 81-91. [CrossRef]

8. Underschultz, J.R.; Vink, S.; Garnett, A. Coal seam gas associated water production in Queensland: Actual vs predicted. J. Nat. Gas Sci. Eng. 2018, 52, 410-422. [CrossRef]

9. Gentzis, T.; Bolen, D. The use of numerical simulation in predicting coalbed methane producibility from the Gates coals, Alberta Inner Foothills, Canada: Comparison with Mannville coal CBM production in the Alberta Syncline. Int. J. Coal Geol. 2008, 74, 215-236. [CrossRef]

10. Ozdemir, E. Modeling of coal bed methane (CBM) production and $\mathrm{CO}_{2}$ sequestration in coal seams. Int. J. Coal Geol. 2009, 77, 145-152. [CrossRef]

11. Zheng, G.Q.; Pan, Z.J.; Chen, Z.W.; Tang, S.H.; Connel, L.D.; Zhang, S.H.; Wang, B. Laboratory study of gas permeability and cleat compressibility for CBM/ECBM in Chinese coals. Energy Explor. Exploit. 2012, 30, 451-476. [CrossRef]

12. Massarotto, P.; Lyer, R.S.; Elma, M.; Nicholson, T. An experimental study on characterizing coal bed methane (CBM) fines production and migration of mineral matter in coal beds. Energy Fuels 2014, 28, 766-773. [CrossRef]

13. Yan, F.Z.; Lin, B.Q.; Zhu, C.J.; Shen, C.M.; Zou, Q.L.; Guo, C.; Liu, T. A novel ECBM extraction technology based on the integration of hydraulic slotting and hydraulic fracturing. J. Nat. Gas. Sci. Eng. 2015, 22, 571-579. [CrossRef]

14. Yuan, B.; Wood, D.A.; Wu, W. Stimulation and Hydraulic Fracturing Technology in Natural Gas Reservoirs: Theory and Case Studies (2012-2015). J. Nat. Gas Sci. Eng. 2015, 26, 1508-1509. [CrossRef]

15. Zhou, J.; Chen, M.; Jin, Y. Analysis of fracture propagation behavior and fracture geometry using a tri-axial fracturing system in naturally fractured reservoirs. Int. J. Rock Mech. Min. Sci. 2008, 45, 1143-1152. [CrossRef]

16. Cheng, W.; Jin, Y.; Lin, Q.; Chen, M.; Zhang, Y.K.; Diao, C.; Hou, B.; Lupton, N. Experimental investigation about influence of pre-existing fracture on hydraulic fracture propagation under tri-axial stresses. Geotech. Geol. Eng. 2015, 33, 467-473. [CrossRef]

17. Cheng, W.; Jin, Y.; Chen, M. Reactivation mechanism of natural fractures by hydraulic fracturing in naturally fractured shale reservoirs. J. Nat. Gas. Sci. Eng. 2015, 23, 431-439. [CrossRef]

18. Guo, T.K.; Zhang, S.C.; Zhan, Q.Q.; Zhou, T.; Xiao, Y.S. Experimental study of hydraulic fracturing for shale by stimulated reservoir volume. Fuel 2014, 128, 373-80. [CrossRef]

19. Wright, C.A.; Tanigawa, J.J.; Mei, S.; Li, Z. Enhanced hydraulic fracture technology for a Coal Seam Reservoir in Central China. In Proceedings of the International Meeting on Petroleum Engineering, Beijing, China, 14-17 November 1995; pp. 1-13.

20. Bohloli, B.; de Pater, C.J. Experimental study on hydraulic fracturing of soft rocks: Influence of fluid rheology and confining stress. J. Pet. Sci. Eng. 2006, 53, 1-12. [CrossRef]

21. Li, L.C.; Li, G.; Wang, S.Y.; Liang, Z.Z.; Zhang, Y.B. Numerical simulation of $3 d$ hydraulic fracturing based on an improved flow-stress-damage model and a parallel fem technique. Rock Mech. Rock Eng. 2012, 45, 801-818. [CrossRef]

22. Wang, T.; Zhou, W.B.; Chen, J.H.; Xiao, X.; Li, Y.; Zhao, X.Y. Simulation of hydraulic fracturing using particle flow method and application in a coal mine. Int. J. Coal Geol. 2014, 121, 1-13. [CrossRef]

23. Zhang, J.C. Numerical simulation of hydraulic fracturing coalbed methane reservoir. Fuel 2014, 136, 57-61. [CrossRef]

24. Yang, T.H.; Zhu, W.C.; Yu, Q.L.; Liu, H.L. The role of pore pressure during hydraulic fracturing and implications for groundwater outbursts in mining and tunneling. Hydrogeol. J. 2011, 19, 995-1008. [CrossRef] 
25. Holditch, S.A. Enhanced recovery of Coalbed Methane through hydraulic fracturing. In Proceedings of the SPE Annual Technical Conference and Exhibition, Houston, TX, USA, 2-5 October 1988; pp. 1-9.

26. Zou, Y.S.; Zhang, S.C.; Zhang, J. Experimental Method to Simulate Coal Fines Migration and Coal Fines Aggregation Prevention in the Hydraulic Fracture. Transp. Porous Med. 2014, 101, 17-34. [CrossRef]

27. Pandey, V.J.; Flottmann, T.; Zwarich, N.R. Applications of Geomechanics to Hydraulic Fracturing: Case Studies from Coal Stimulations. Soc. Pet. Eng. 2017, 32. [CrossRef]

28. Johnson, R.L.; Scott, M.P.; Jeffrey, R.G.; Chen, Z.R. Evaluating Hydraulic Fracture Effectiveness in a Coal Seam Gas Reservoir from Surface Tiltmeter and Microseismic Monitoring. J. Pet. Technol. 2010, 63, 59-62.

(C) 2018 by the authors. Licensee MDPI, Basel, Switzerland. This article is an open access article distributed under the terms and conditions of the Creative Commons Attribution (CC BY) license (http:/ / creativecommons.org/licenses/by/4.0/). 